OPEN ACCESS

Edited by:

Allen Ho,

Stanford University, United States

Reviewed by:

Shweta Tiwary,

National Cancer Institute (NIH),

United States

Yuhao Huang,

Stanford University, United States

*Correspondence:

Anwen Shao

21118116@zju.edu.cn;

anwenshao@sina.com

Qichun Wei

qichun_wei@zju.edu.cn

Specialty section:

This article was submitted to

Neuro-Oncology and Neurosurgical

Oncology,

a section of the journal

Frontiers in Oncology

Received: 28 February 2020

Accepted: 17 August 2020

Published: 11 September 2020

Citation:

Shao Z, Liu L, Zheng Y, Tu S,

Pan Y, Yan S, Wei Q, Shao A and Zhang J (2020) Molecular Mechanism and Approach in Progression

of Meningioma.

Front. Oncol. 10:538845.

doi: 10.3389/fonc. 2020.538845

\section{Molecular Mechanism and Approach in Progression of Meningioma}

\author{
Zhiwei Shao', Lihong Liu', Yanghao Zheng ${ }^{3}$, Sheng Tư ${ }^{3}$, Yuanbo Pan ${ }^{4}$, Sheng Yan', \\ Qichun Wei ${ }^{2 *}$, Anwen Shao ${ }^{4 *}$ and Jianmin Zhang ${ }^{4,5,6}$
}

${ }^{1}$ Department of Hepatobiliary and Pancreatic Surgery, Second Affiliated Hospital, School of Medicine, Zhejiang University, Hangzhou, China, ${ }^{2}$ Department of Radiation Oncology, The Second Affiliated Hospital, Zhejiang University School of Medicine, Hangzhou, China, ${ }^{3}$ State Key Laboratory for Diagnosis and Treatment of Infectious Diseases, Collaborative Innovation Center for Diagnosis and Treatment of Infectious Diseases, The First Affiliated Hospital, College of Medicine, Zhejiang University, Hangzhou, China, ${ }^{4}$ Department of Neurosurgery, Second Affiliated Hospital, School of Medicine, Zhejiang University, Hangzhou, China, ${ }^{5}$ Brain Research Institute, Zhejiang University, Hangzhou, China, ${ }^{6}$ Collaborative Innovation Center for Brain Science, Zhejiang University, Hangzhou, China

Meningioma is the most common tumor of the central nervous system, most of which is benign. Even after complete resection, a high rate of recurrence of meningioma is observed. From in-depth study of its pathogenesis, it has been found that a number of chromosomal variations and abnormal molecular signals are closely related to the occurrence and development of malignancy in meningioma, which may provide the theoretical basis and potential direction for accurate and targeted treatment. We have reviewed advances in chromosomal variations and molecular mechanisms involved in the progression of meningioma, and have highlighted the association with malignant biological behavior including cell proliferation, angiogenesis, increased invasiveness, and inhibition of apoptosis. In addition, the chemotherapy of meningioma is summarized and discussed.

Keywords: meningioma, mechanism, genetics, chromosomal abnormality, apoptosis, invasiveness, angiogenesis

\section{INTRODUCTION}

The meninges consist of the dura mater, arachnoid and pia mater, which envelope the surface of the brain and spinal cord. A tumor produced in the meninges is known as a meningioma (1). According to the latest statistical report of the Central Brain Tumor Registry of the United States (CBTRUS), meningioma has become the tumor with the highest rate of incidence of the central nervous system, accounting for approximately $37.1 \%$ (2). Meningioma is common in elderly patients, the median age of diagnosis being 66 years of age. Females are approximately 2.2 -fold more likely to develop meningioma than males, except in atypical and anaplastic meningioma, where males outnumber female patients (2). The World Health Organization (WHO) classifies meningioma into grade I benign meningioma $(>80 \%)$, grade II atypical meningioma (15-20\%), and grade III anaplastic meningioma (1.0-3.0\%) $(2,3)$. Meningioma can be further divided into 15 subtypes according to histopathology (4). Among them, meningothelial, fibroblastic, and transitional meningioma are the most common subtypes of the WHO (5). By comparing the immunophenotypes of normal arachnoid and meningiomas, research data indicate that arachnoid cap cells are likely to be the precursor cells of meningioma (6). Finally, a study established that prostaglandin D2 synthase (PGDS) positive arachnoid cells are the origin cells of meningiomas (7). Surgical resection can cure $70-80 \%$ of meningioma. However, atypical and anaplastic meningioma often have high 
recurrence rates, strong invasiveness and poor prognosis. Even after complete resection, the rate of recurrence of atypical and anaplastic meningioma is still as high as 50\% and $80 \%$, respectively (8). Furthermore, approximately $20 \%$ of meningioma with benign histology are likely to in fact be invasive and recurrent, which affects the treatment of the tumor (9). Previous studies have identified multiple molecular targets and genetic alterations that contribute to its progression, including those related to cell proliferation, increased invasiveness, angiogenesis, and inhibition of apoptosis. These molecular targets may be targeted in future to improve the therapeutic effect. Here, we summarize the molecular mechanisms that drive the biological behavior and relative medical treatment of meningioma.

\section{CYTOGENETICS}

The most common chromosomal abnormality in meningioma is in chromosome 22 , observed in $40-70 \%$ of grade I meningioma. Beyond the loss of chromosome 22, few other chromosomal abnormalities have been observed in benign meningioma (10). In an analysis of chromosome 22 in 44 sporadic meningiomas, researchers found that in 43 cases, all or part of the chromosome had been deleted, the majority of deletions occurring in the neurofibromatosis type 2 (NF2) region, suggesting that the mutation on NF2 leads to the occurrence of meningioma (11). In addition, a number of studies have demonstrated that loss of gene function of NF2 contributes to develop schwannoma, ependymomas, and malignant mesothelioma (1214). Mice lacking NF2 are prone to develop cancers such as osteosarcoma, lymphoma, lung adenocarcinoma, hepatocellular carcinoma (HCC), and fibrosarcoma (15). Research has suggested that NF2 promotes contact inhibition and tumor suppression by suppressing mitogenic signaling at the cellular cortex (16). Therefore, the inactivation of NF2 plays an important role in early oncogenic events. Atypical and anaplastic meningioma exhibit a greater number of chromosomal abnormalities than benign meningioma, but the frequency of the NF2 gene mutations is almost the same as in benign meningioma, indicating that NF2 may not be related to the progression of meningioma (17). Loss of chromosome 1 is detected more often in atypical and anaplastic meningioma, and is the second most common deletion site in meningioma (1). The rate of deletion of $1 \mathrm{p}$ is significantly correlated with grade of meningioma (grade I meningioma: 13-26\%; grade II: $40-76 \%$; and grade III: $70-$ $100 \%)$. Loss of $1 \mathrm{p}$ is also associated with malignant progression of meningioma (18). In atypical meningioma, chromosomal loss of $1 \mathrm{p}, 6 \mathrm{q}, 10,14 \mathrm{q}$, and $18 \mathrm{q}$, and gains at $1 \mathrm{q}, 9 \mathrm{q}, 12 \mathrm{q}, 15 \mathrm{q}, 17 \mathrm{q}$, and $20 \mathrm{q}$ have been observed. On the basis of the mutations described above, losses are more frequent at $6 \mathrm{q}, 9 \mathrm{p}, 10$, and $14 \mathrm{q}$ with amplification of $17 \mathrm{q} 23$ in anaplastic meningioma (3) (Figure 1). In terms of chromosomal mutation and incidence of relapse in meningioma, researchers have used fluorescence in situ hybridization (iFISH) analysis on 302 meningioma samples, finding that alterations in $1 \mathrm{p}, 1 \mathrm{q}, 7,9,10,14,18$, and 22 chromosome were significantly related to the incidence of relapse
(19). Chromosomal variations provide a genetic basis for the stepwise progression of meningioma, which greatly assists in the diagnosis of grade and prognosis. Recent studies have also shown that the location of meningiomas is related to mutational profile. Compared with other anatomic locations, NF2 mutations are more common in the lateral regions and posterior skull base meningiomas, while the most majority of non-NF2 meningiomas often locate in the anterior, medial, or skull base regions $(1,20)$. For example, meningiomas with Smoothened (SMO) mutation are more likely to localize to the medial anterior skull base, near the midline (20). Meningiomas with Krueppel-like-factor 4 (KLF4)/TNF receptor-associated factor 7 (TRAF7) mutation often locate in the medial skull base and v-akt murine thymoma viral oncogene homolog 1 (AKT1)/TRAF7 mutation in the anterior skull base (21).

\section{GENETIC ALTERATIONS WITH CLINICAL PROGNOSIS}

The genetic changes of meningioma is associated with the poor prognosis. A study have shown that activating mutations in the promoter of the telomerase reverse transcriptase (TERT) gene promote the aggressiveness of meningiomas and reduce the survival of patients (22). Patients with TERT promoter mutation had significantly shorter overall survival (53.8 vs 115.6 months; $P=0.0006)$. Another study also demonstrated that patients with TERT promoter mutation had a higher risk of recurrence and a shorter time to progression, regardless of WHO grade (23). In a study of 169 meningioma samples, Dystrophin-encoding and Muscular Dystrophy-associated gene (DMD) inactivation (by genomic deletion or loss of protein expression) was detected in $32 \%$ of patients with progressive meningiomas. Patients with DMD inactivation had significantly shorter overall survival than wild-type counterparts [5.1 years (95\% CI 1.3-9.0) vs. median not reached (95\% CI 2.9-not reached), $p=0.006$ ] (24). Breast cancer (BRCA)1-associated protein-1 (BAP1) is a tumor suppressor gene encoding for a deubiquitylating enzyme. A study have demonstrated that BAP1-deficient meningiomas are more aggressive and have a poor prognosis (25).

\section{MOLECULAR MECHANISMS OF CHANGE IN BIOLOGICAL BEHAVIOR}

\section{Abnormal Cell Growth and Proliferation}

The growth and proliferation of tumor cells are closely related to cell cycle dysregulation. For example, abnormal expression of cyclin, cyclin dependent kinases or their inhibitors often leads to enhanced proliferation and differentiation of meningioma cells $(26,27)$. The cyclin-dependent kinase inhibitor 2A (CDKN2A) gene can encode a variety of cell cycle regulating proteins including p16 [inhibitor of CDK4 (INK4a)] and p14 [alternative reading frame $(\mathrm{ARF})]$ that inhibit the growth of tumor cells. Of these, the former principally inhibits the activity of cyclin dependent kinase 4 (CDK4) and 6 (CDK6), while the latter inhibits the degradation of tumor suppressor protein p53 that 


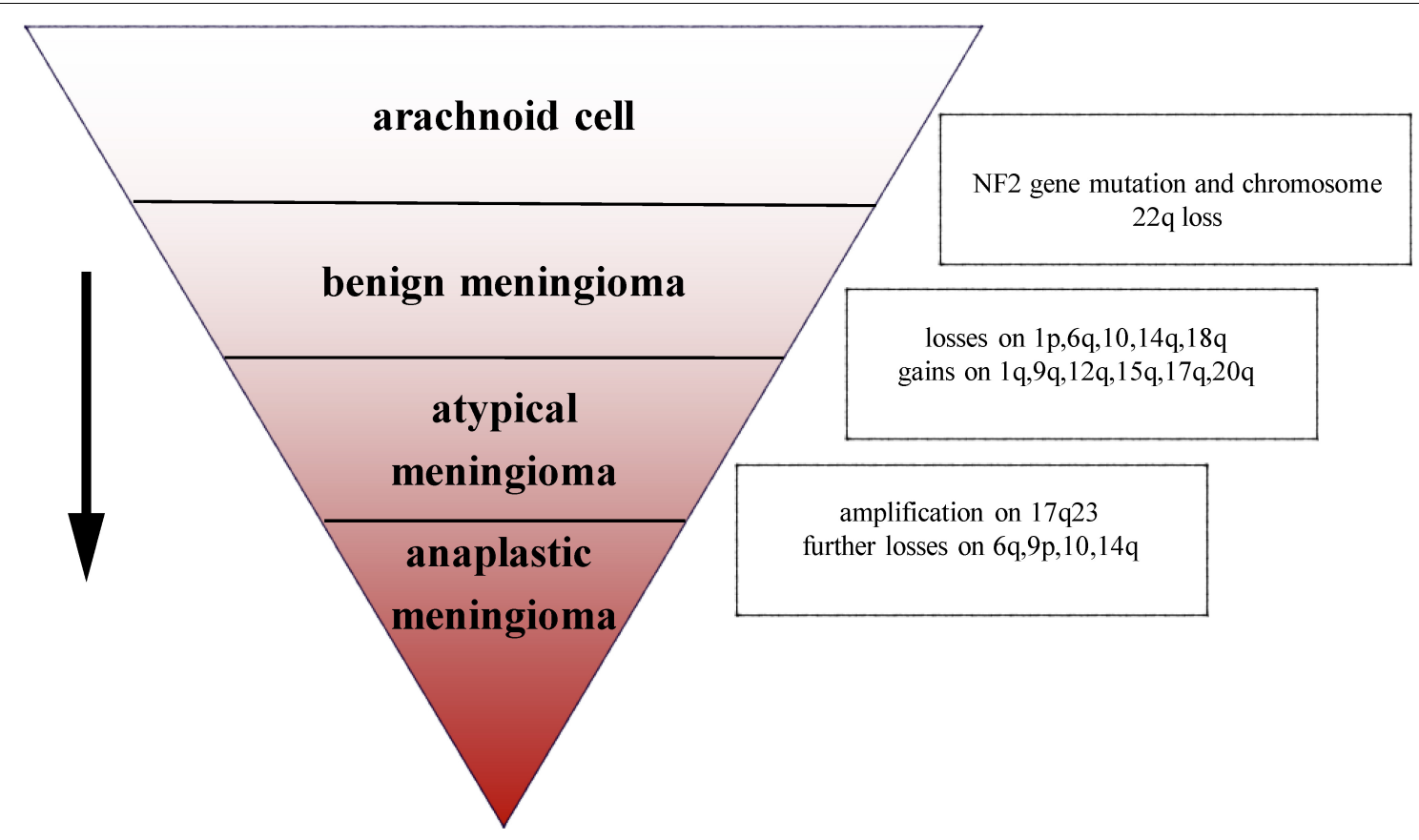

FIGURE 1 | Chromosomal abnormalities in the progression of meningioma.

controls $\mathrm{G} 1 / \mathrm{S}$ phase transition $(8,26)$. One study that compared the gene coding sequences of recurrent and non-recurrent meningioma found that changes in the CDKN2A gene were only observed in recurrent meningioma (28). The deletion of the CDKN2A gene promoted the malignant progression of meningioma, indicating poor outcome (29). Cyclin D1 (CCND1) controls the transition of the cell cycle, principally regulating the G1-S phase, and playing an important role in the transcription of tumor genes and cell proliferation (30). It has been reported that cyclin D1 is overexpressed in meningioma, and positively correlated with the degree of malignancy and rate of recurrence in meningioma. Knockdown of cyclin D1 expression in the meningioma cell lines IOMMLee and $\mathrm{CH} 57$ demonstrated inhibition of the growth and proliferation of the cells (27). Forkhead box protein M1 (FoxM1) is a pro-mitotic transcription factor, which plays a positive regulatory role in the $\mathrm{G} 1 / \mathrm{S}$ and $\mathrm{G} 2 / \mathrm{M}$ transition of the cell cycle, ensuring smooth progression of mitosis (31). A separate study showed that an increase in FoxM1 expression can be observed in higher-grade meningioma, promoting the expression of $\beta$-catenin and cyclin D1, finally leading to proliferation and colony formation in meningioma cells (32). Similarly, overexpression of FoxM1 was also found in recurrent meningioma (32). A single transcriptome analysis, including the analysis of 280 human meningioma samples, demonstrated that FoxM1 plays a critical role in the proliferation of meningioma, indicating poor clinical prognosis (33). Cell cycle related proteins topoisomerase II $\alpha$ and mitosin control the condensation and separation of mitotic chromosomes (34). A retrospective study of 160 meningioma patients found that patients with high topoisomerase II $\alpha$ and mitosin expression suffered a higher risk of recurrence (35). Rapamycin [mammalian target of rapamycin (mTOR)] is mainly regulated by the phosphoinositide-3-kinase $(\mathrm{PI} 3 \mathrm{~K}) /$ protein kinase $\mathrm{B}(\mathrm{Akt})$ pathway, and is over-activated in both sporadic and hereditary brain tumors, related to cell growth, differentiation and tumorigenesis (36) (Figure 2). A study of human meningioma cell lines found that meningioma with over-expression of osteoglycin (OGN) exhibited higher cell proliferation, cell cycle activation and colony formation rate, activities closely associated with the PI3K/Akt/mTOR pathway (37). Inhibition of this pathway significantly suppressed abnormal cell proliferation and increased cell death. Yesilöz et al. analyzed 93 samples of skull base meningiomas, finding that over-activation of the mTOR signaling pathway was closely associated with the recurrence of meningioma (38). Another study demonstrated that the high expression of mTOR in atypical meningioma led to an increase in mitotic index, and meningioma which had high expression of mTOR exhibited worse prognosis (39).

\section{Increased Cell Invasiveness}

The adhesiveness of malignant cells is usually lower than that of normal cells. It was found that various cell adhesion molecules are expressed abnormally during the malignant invasion of meningioma. E-cadherin (encoded by $\mathrm{CDH} 1$ at 16q22.1) is a calcium-dependent adhesion molecule, mediating their interaction with epithelial cells (40). It relies on $\beta$ catenin to play a role in cell adhesion, which is considered an indirect regulator of the Wnt signaling pathway (10). E-cadherin and $\beta$-catenin comprise the E-cadherin/catenin complex that regulates cell adhesion and maintains cell polarity and stability (40). A low expression or absence of E-cadherin leads to the 


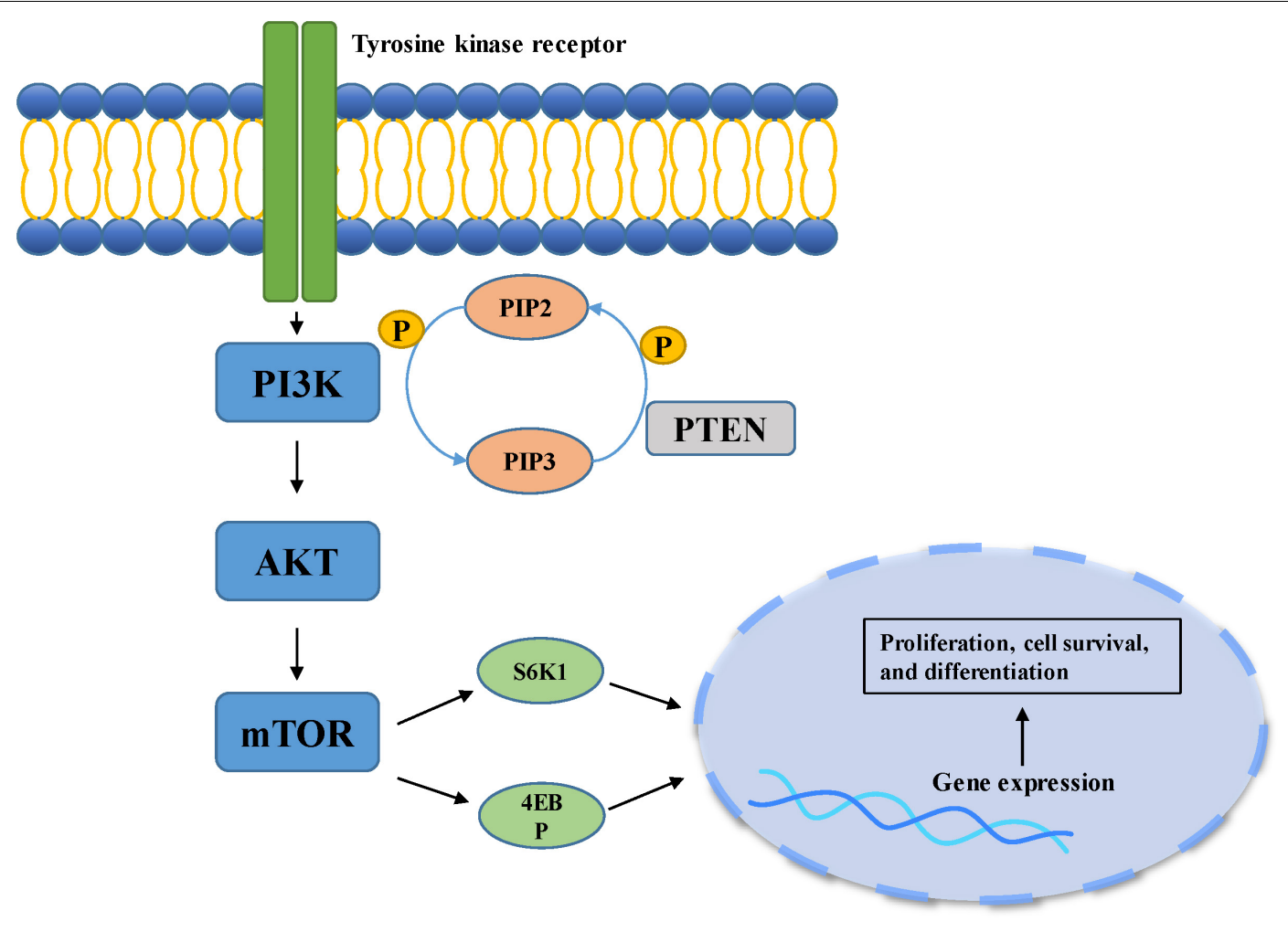

FIGURE 2 | PI3K/Akt pathway is involved in cell growth, differentiation, and tumorigenesis. When the ligand binds to the membrane receptor, the receptor activates $\mathrm{PI} 3 \mathrm{~K}$, which then catalyzes the formation of PI3P from PIP2 on the inner surface of the membrane. As the second messenger, PI3P further activated Akt. Akt can activate the downstream mTOR pathway, which can phosphorylate and activate S6K1 and 4EBP, and finally participate in gene expression.

reduced formation of the complex, contributing to a decrease in adhesion between epithelial cells, the loss of intercellular connections, in addition to the weakening of contact inhibition, eventually leading to the uncontrolled growth of tumor cells and invasion of surrounding tissues $(41,42)$. Immunostaining of E-cadherin in 60 meningioma samples demonstrated that the expression of E-cadherin was down-regulated in $73 \%$ of meningioma. Moreover, E-cadherin has a more apparent downregulatory effect in grade II and III meningiomas (43). Other studies of E-cadherin in meningioma have drawn similar conclusions. One study demonstrated negative expression of E-cadherin in all atypical meningioma, concluding that the increased invasiveness of meningioma is partly due to the loss of E-cadherin (44). Another study reported a positive correlation between the low expression of E-cadherin and the invasiveness of meningioma (45). Matrix metalloproteinases (MMPs) are zinc-dependent endopeptidases involved in the degradation of the extracellular matrix and tissue reconstruction, found to be closely associated with malignant invasion and distant metastasis of tumor cells (46). A number of reports have suggested that MMP-9 can promote the occurrence and development of tumors (47-50). Previous studies have shown that the expression of MMP-9 in meningioma is significantly correlated with the degree of malignancy and invasiveness. In the malignant meningioma cell lines IOMM-Lee and CH157MN, MMP-9 has been shown to be significantly up-regulated with increased expression of the lncRNA LINC00460, leading to the progression of meningioma (51). The expression of MMP-9 in different grades of meningiomas has also been studied (52). Results of immunohistochemical analysis indicated that more MMP-9 was expressed in grade II and III meningiomas. Another study showed increased expression of MMP-9 in meningioma cells following irradiation (53). The authors confirmed increased invasiveness of the cells through spheroid migration and Matrigel invasion assays. The ability of cells to invade was reversed by the down-regulation of MMP-9. Petermann et al. found that loss of density-enhanced phosphatase-1 (DEP-1; a transmembrane protein-tyrosine phosphatase) reduced the adhesion of cell matrix, and enhanced the migration and invasive growth of meningioma cells (54). In the following experiments, Petermann et al. studied the relationship between DEP-1 and the invasiveness of meningioma cells (55). They found increased MMP-9 expression in DEP-1-depleted meningioma cells using zymography, suggesting that up-regulation of MMP9 may contribute to the aggressive growth of meningioma. A recent study also demonstrated that the deficiency of DEP1 promotes the progression of meningioma (56). A separate study demonstrated that the expression levels of tissue inhibitor of metalloproteinases-1 (TIMP-1) in invasive meningioma is significantly lower than that in non-invasive meningioma, possibly related to the inhibition of MMP-9 activity by TIMP-1 (57). The expression of A-kinase anchor protein 12 (AKAP12) 


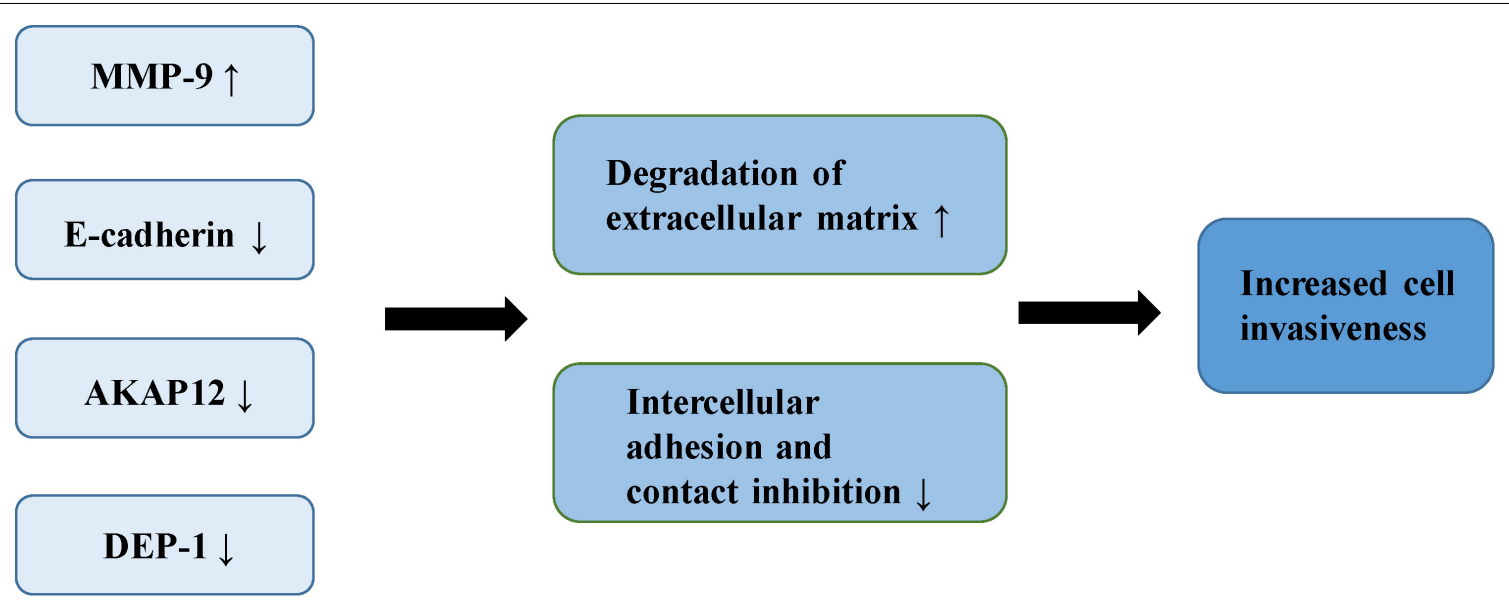

FIGURE 3 | The mechanism of increased invasiveness in meningioma.

increased in actively migrating cells, believed to play an important role in actin dynamics and actin filament-based migration (58). It is known that the expression of AKAP12 is inhibited in a number of human malignant tumors, such as melanoma, HCC, gastric cancer and BRCA (59-62). It has been found that knock-down of AKAP12 can promote the migration and invasion of meningioma cells, indicating that AKAP12 plays a possible role in inhibition of the progression of meningioma (63) (Figure 3).

\section{Angiogenesis}

Meningioma is a vascular-rich type of tumor, especially atypical and anaplastic meningioma, which are likely to relapse, suggesting that angiogenesis plays an important role in its malignant-type behavior (64). In a study of the molecular mechanism of tumor angiogenesis, Bergers proposed the theory of an "angiogenic switch," that is, the dynamic balance of angiogenic and antiangiogenic factors which becomes broken, allowing the interaction of these factors to affect the biological behavior of meningioma, such as angiogenesis and invasion (65). Vascular endothelial growth factor (VEGF) is considered among the most important angiogenic factors, involved in multiple physiological and pathological pathways of angiogenesis. One study established that VEGF and its receptor are up-regulated in the hypoxic tissues of recurrent meningioma, inducing new angiogenesis to alleviate the hypoxia. Microvessel density (MVD) is closely related to poor prognosis in meningioma (66). In a study of 40 meningioma samples, a group of researchers found positive correlation between VEGF expression and pathological grade of meningiomas by immunohistochemistry (67). Hypoxia inducible factor-1 alpha (HIF-1 $\alpha$ ), an upstream regulator of a variety of signaling pathways, regulates many tumor metabolic processes, such as glycolysis, apoptosis, angiogenesis, and promotion of tumor growth (68). HIF-1 $\alpha$ activates VEGF transcription via the PI3K/Akt signaling pathway, up-regulating VEGF expression and promotes endothelial cell proliferation in meningioma (69). In addition, over-expression of HIF- $1 \alpha$ can increase the stability of VEGF and its receptor, and promote neovascularization (70).
One study found that silencing of HIF- $3 \alpha$ (an HIF- $1 \alpha$ inhibitor) suppresses angiogenesis and proliferation in meningioma (71). As the upstream regulatory gene of VEGF, signal transducer and activator of transcription factor 3 (Stat-3), it regulates the expression of VEGF through the JAK/STAT signaling pathway combined with the promoter of VEGF, promoting tumor angiogenesis (72). Kwon et al. confirmed that MMP-9 is expressed to a significant level in meningioma, closely related to neovascularization and tumor cell migration (73). A study of malignant meningioma cell lines found that the expression of MMP-9 was silenced by small interfering RNA (siRNA) which could inhibit the formation of a capillary network (74). MMP-9 creates the space and stimulation for angiogenesis by promoting the degradation of extracellular matrix and releasing the VEGF embedded in the extracellular matrix. MMP-9 also enhances the binding function of VEGF and its receptor, and up-regulates the bioavailability of VEGF (74). In 1999, a number of researchers found a type of microcirculatory duct without endothelial cells in melanoma, termed tumor vasculogenic mimicry (VM). Blood is able to flow normally in these acellular tubular structures (75). The VM phenomenon has also been reported in malignant meningioma (76) (Figure 4).

\section{Inhibition of Apoptosis}

Inhibition of apoptosis is closely associated with the occurrence, development and prognosis of tumors in meningioma. Several studies have found that the Wnt signaling pathway plays an important role in the development of meningioma, which is involved in apoptosis (77-79). The main pathway comprises three branches: the classical Wnt/ $\beta$-catenin signal transduction pathway, the planar cell polarity (PCP) pathway and the Wnt$\mathrm{Ca}^{2+}$ pathway (10). Members of the classical pathway include the extracellular Wnt factor, transmembrane receptor, $\beta$-catenin, glycogen synthase kinase-3 $\beta$ (GSK3 $\beta$ ), adenomatous polyposis coli (APC), Axin, and casein kinase-1 (CK1) (10, 80). When the classical Wnt pathway is unactivated, GSK3 $\beta$ in the cytoplasm can phosphorylate $\beta$-catenin in the form of a complex with APC, Axin, and CK1 (81). By recognition of the phosphorylation site 


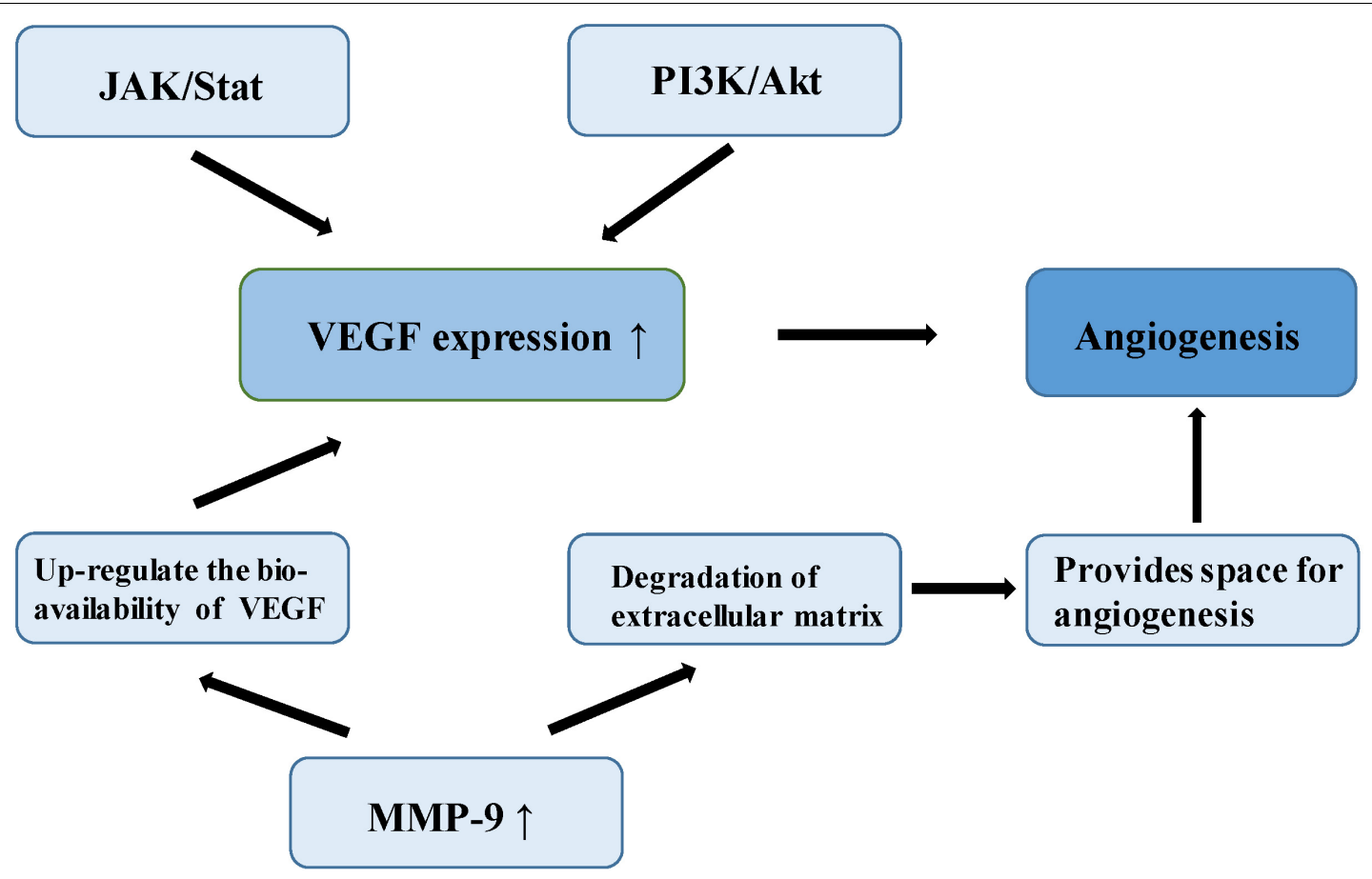

FIGURE 4 | The mechanism of angiogenesis in meningioma.

of $\beta$-catenin, $\beta$-TrCP can ubiquitinate $\beta$-catenin, then degrade it through a proteasome, and maintain a low level of $\beta$-catenin in cells (82). When Wnt signaling is activated, the Wnt protein binds with the extracellular domain of Frizzled (Fz). Through the synergistic effect of the low density lipoprotein receptor related protein (LRP 5/6), dishevelled protein (DVL) in the cytoplasm becomes translocated to the cellular membrane. DVL can phosphorylate GSK3 $\beta$ and lead to disintegration of the complex. In this case, $\beta$-catenin cannot be degraded, and a large number of free $\beta$-catenin aggregates in the cytoplasm and enters the nucleus (83). After $\beta$-catenin is combined with lymphoid enhancer factor (LEF)/T cell factor (TCF) to form a complex, suppression of LEF/TCF is reduced, and transcription of downstream target genes is specifically activated, including c-myc, cyclin D1, CD44, Bcl2, c-jun, etc. $(84,85)$ (Figure 5).

Multiple studies have shown that activation of the Wnt signaling pathway inhibits neural cell apoptosis (86-90). One study of meningioma found that lncRNA SNHG1 can inhibit apoptosis in BEN-1-1 and IOMM-Lee cells via the Wnt pathway, as found through the measurement of TUNEL-positive cells and caspase-3 activity (77). Knockdown of SNHG1 inhibited cell proliferation and promoted apoptosis. In another study, in which down-regulation of lncRNA LINC00702 inhibited Wnt signal activity in malignant meningioma, induction of apoptosis and decreased meningioma cell proliferation were observed (78). Unfortunately, there are few studies of the inhibition of apoptosis via the Wnt signaling pathway in meningioma. However, a large number of reports have been published concerning inhibition of apoptosis through the Wnt signaling pathway in glioma, neuroblastoma, spinal cord injury, and cerebral hemorrhage
(85-91). Therefore, we can reasonably assume that the Wnt signaling pathway plays a role in inhibition of apoptosis in meningioma cells.

Many studies have explored the potential target of antiapoptotic mechanisms in meningioma. One study assessed the expression of CD163 in 50 samples of meningioma (92). Researchers found that $48.5 \%$ and $71.4 \%$ of grade I and II meningioma, respectively, were positive for CD163. They also found human meningioma cell lines in which CD163 was overexpressed exhibited a decrease in apoptosis and hematopoietic cytokines, demonstrating that CD163 prevents apoptosis by production of granulocyte colony-stimulating factor (G-CSF). Other researchers compared the rate of apoptosis in meningioma between the FTS (a Ras inhibitor) group and control group by flow cytometric analysis, finding that apoptosis increased in the FTS group, indicating that Ras inhibition induced apoptosis (93). It has been reported that the expression of let-7d is down-regulated in meningioma, and that its overexpression induces apoptosis (94). In a recent study, researchers found a new oncogenic protein, N-myc downstreamregulated gene 4 (NDRG4), which is overexpressed in aggressive meningioma. After removal of NDRG4, the cells mostly died due to apoptosis (95).

\section{MEDICAL TREATMENT FOR MENINGIOMA}

For the majority of patients with benign meningioma, surgical resection combined with stereotactic radiotherapy is effective in 

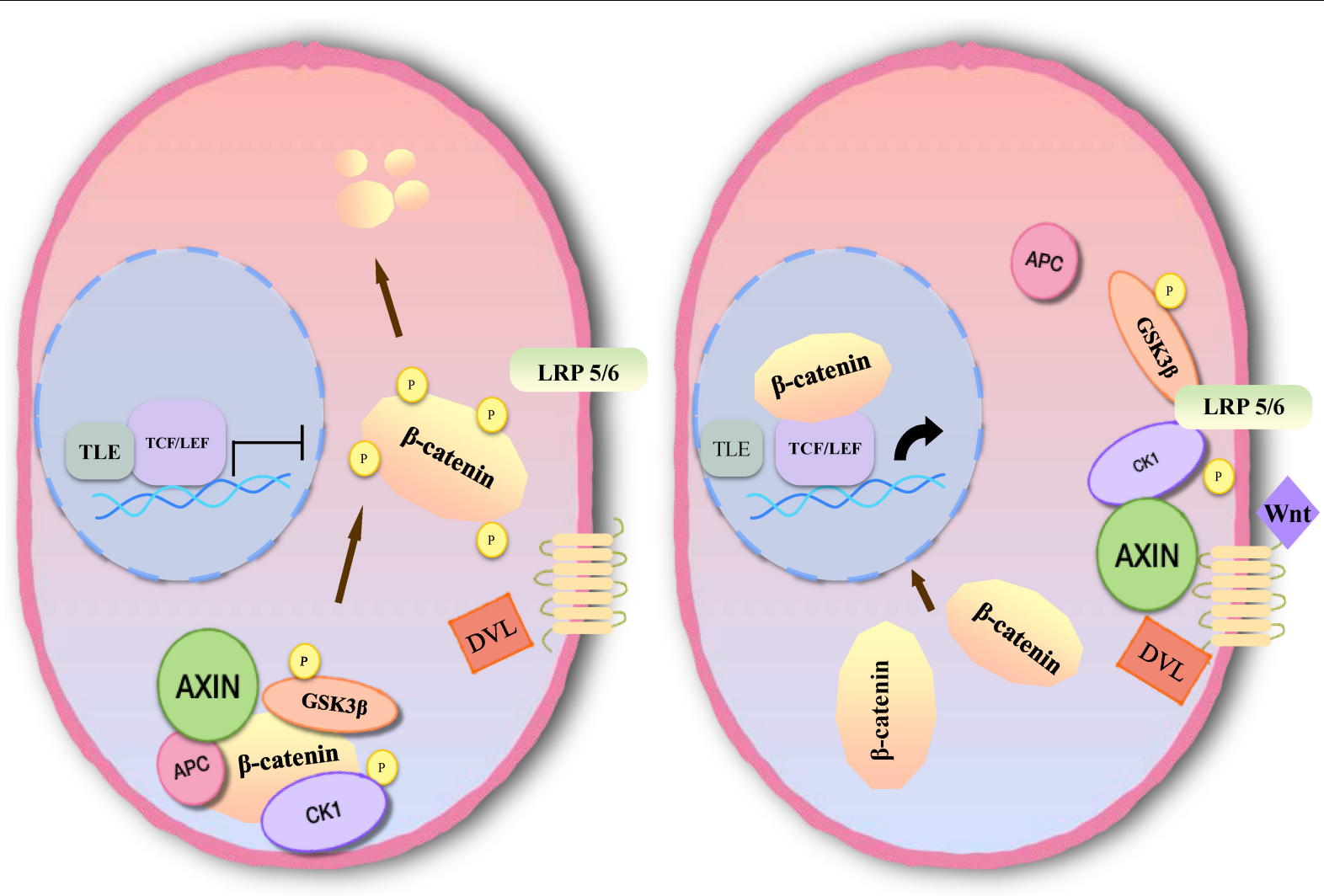

FIGURE 5 | Molecular mechanism of Wnt/ $\beta$-catenin signaling pathway activation.

controlling the disease. However, no standardized treatment for recurrent or progressive meningioma has yet been published. Methods of treatment for meningioma include chemotherapy, molecular targeted therapy, immunotherapy, and hormone therapy, etc. (96).

\section{Molecular Targeted Therapy}

A large number of studies have confirmed that the $\mathrm{PI} 3 \mathrm{~K} / \mathrm{Akt} / \mathrm{mTOR}$ pathway is overactive in meningioma, which has a close association with cell growth, differentiation and tumorigenesis, suggesting that mTOR is a potential therapeutic target for meningioma. In an in vitro experiment, eight mice with subcutaneous IOMM-Lee xenografts were treated with mTOR inhibitors (97). Growth of the tumor cells was significantly inhibited. A recent phase II trial of progressive meningioma achieved satisfactory results (98). Twenty patients with meningioma (including 18 non-benign meningioma) were treated with everolimus (an mTOR inhibitor) and octreotide (a somatostatin agonist). The overall PFS-6 was $55 \%$, and a 6 - and 12 -month overall survival was $90 \%$ and $75 \%$, respectively. Tumor growth rate decreased significantly after 3 months in $78 \%$ patients, and median tumor growth rate decreased from an initial $16.6 \%$ to $0.02 \%$. Octreotide inhibits the phosphorylation of the PI3K/Akt pathway and activates tyrosine phosphatase, which can inhibit the proliferation of tumor cells in vitro (99). One study demonstrated that octreotide promotes the antitumor effect of everolimus in aggressive meningioma (100). Because a meningioma is a vascular-rich tumor, reduction in angiogenesis may be beneficial for treatment. VEGF is an important angiogenic regulatory molecule, which positively correlates with the pathological grade of meningioma. The expression levels of VEGF in atypical and anaplastic meningioma have been found to be 2 and 10 times higher than in benign meningioma, respectively (101). A retrospective study of 15 patients of atypical or anaplastic meningioma treated with bevacizumab (a VEGF inhibitor) found that the progression-free survival (PFS) rate was $43.8 \%$ at 6 months, with a median PFS of 26 weeks (102). Similarly, another retrospective study in which 14 patients with progressive meningioma were enrolled (including 5 patients with grade I meningioma) found that PFS at 6 months following treatment with bevacizumab was $86 \%$ (103). A phase II clinical trial evaluated the response of patients with advanced meningioma to combination treatment consisting of bevacizumab and everolimus (104). A total of 17 patients were treated, 15 of whom exhibited stable disease progression, with a median disease stabilization period of 10 months. An ongoing phase II clinical trial (NCT02847559) aims to test the efficacy of the combination of electric field therapy and bevacizumab in patients with recurrent or progressive meningioma. A separate phase II clinical trial recruited 36 patients with high-grade meningioma who were treated with sunitinib [a VEGF and 
platelet derived growth factor (PDGF) inhibitor], finding that median PFS was 1.4 and 6.4 months in VEGFR2 negative and positive patients, respectively (105). Despite the significant side effects (grade 3 or higher toxicity in $60 \%$ of patients), this clinical trial provides strong evidence for the potential targeting of VEGF in meningioma treatment.

\section{Other Treatments}

Chemotherapy is not effective for the treatment of malignant meningioma, and is usually only used when the initial treatment fails or the tumor relapses (106). Timozolomide and irinotecan, which are efficient therapies for specific intracranial tumors, had no apparent therapeutic effect on meningioma $(107,108)$. Hydroxyurea is the most well-studied chemotherapeutic drug in advanced meningioma, and this exhibits a certain therapeutic effect (109). Interferon-alpha is a biologic agent able to inhibit DNA synthesis. In the early experiments of meningioma in vitro, interferon-alpha exhibited inhibitory activity toward the growth of tumor cells (110). A phase 2 study evaluated the efficacy of interferon-alpha in the treatment of WHO grade I recurrent meningioma, and found that the PFS rate was 54\% at 6 months, demonstrating pharmaceutical activity (111).

Immunotherapy is a potential treatment regimen for malignant meningioma. It has been found that the expression of programmed death-ligand receptor (PD-L1) is increased in meningioma, especially in anaplastic meningioma (112). Therefore, two phase 2 clinical trials of treatments for high-grade meningioma are in progress, using nivolumab (NCT02648997), and pembrolizumab (NCT03016091), respectively. With the discovery of progesterone receptor (PR) in meningioma cells, the use of mifepristone (an antagonist of progesterone) in the treatment of meningioma patients has gradually attracted the attention of researchers (113). It has been reported that in 3 cases of meningioma treated with mifepristone, 2 cases exhibited radiological regression and 1 case was stable (114). A phase II clinical study showed moderate clinical improvement following treatment with mifepristone in meningioma (115). However, the first and only randomized phase III trial for unresectable meningioma demonstrated the opposite result. There was no significant difference in PFS in the mifepristone and placebo groups 10 months (95\% CI 7-13 months) vs. 11 months (95\%

\section{REFERENCES}

1. Al-Rashed M, Foshay K, Abedalthagafi M. Recent advances in meningioma immunogenetics. Front Oncol. (2019) 9:1472. doi: 10.3389/fonc.2019.01472

2. Ostrom QT, Gittleman H, Truitt G, Boscia A, Kruchko C, Barnholtz-Sloan JS. CBTRUS statistical report: primary brain and other central nervous system tumors diagnosed in the United States in 2011-2015. Neuro Oncol. (2018) 20:iv1-86. doi: 10.1093/neuonc/noy131

3. Choy W, Kim W, Nagasawa D, Stramotas S, Yew A, Gopen Q, et al. The molecular genetics and tumor pathogenesis of meningiomas and the future directions of meningioma treatments. Neurosurg Focus. (2011) 30:E6. doi: 10.3171/2011.2.FOCUS1116

4. Preusser M, Brastianos PK, Mawrin C. Advances in meningioma genetics: novel therapeutic opportunities. Nature reviews. Neurology. (2018) 14:10615. doi: $10.1038 /$ nrneurol.2017.168
CI 6-18 months) (116). The failure of these chemotherapy agents in clinical studies is probably due to the wide molecular heterogeneity of meningiomas.

Unfortunately, at present, there are no strong clinical data showing that medical therapy has a significant effect on meningiomas. Moreover, the sample size of most relevant clinical trials is less than 20 patients. If we consider WHO grade, we will find that these clinical trials also include grade I meningiomas that do not normally require such second-line treatment. These data may influence the real beneficial effects of medical therapy on meningiomas. A greater number of randomized clinical trials are required to provide evidence for the medical treatment of meningioma.

\section{CONCLUSION}

Meningioma is the most common tumor of the central nervous system, and most are considered benign. However, meningioma has a high recurrence rate, and the treatment of malignant meningioma is limited. Specially, the research on molecular mechanism and genetics treatment is insufficient compared with glioma. In this review, we focus on the molecular mechanism to elucidate the changes of biological behavior in the meningioma progression, including cell proliferation, increased invasiveness, angiogenesis, and inhibited apoptosis. Related signaling pathways and protein biomarkers may provide the direction and theoretical basis for the accurate targeted therapy of meningioma in the future.

\section{AUTHOR CONTRIBUTIONS}

ZS, YZ, ST, and YP drafted the manuscript. AS and JZ reviewed and modified the manuscript. LL, SY, and QW revised the manuscript. All authors agreed on the final version.

\section{FUNDING}

This work was funded by National Natural Science Foundation of China (81701144 and 81870916).

5. Dn Louis A, Perry G, Reifenberger A, von Deimling, Figarella-Branger D, Cavenee WK, et al. The 2016 World Health Organization classification of tumors of the central nervous system: a summary. Acta Neuropathol. (2016) 131:803-20. doi: 10.1007/s00401-016-1545-1

6. Tohma Y, Yamashima T, Yamashita J. Immunohistochemical localization of cell adhesion molecule epithelial cadherin in human arachnoid villi and meningiomas. Cancer Res. (1992) 52:1981-7.

7. Kalamarides M, Stemmer-Rachamimov AO, Niwa-Kawakita M, Chareyre F, Taranchon E, Han ZY, et al. Identification of a progenitor cell of origin capable of generating diverse meningioma histological subtypes. Oncogene. (2011) 30:2333-44. doi: 10.1038/onc.2010.609

8. Lee YS, Lee YS. Molecular characteristics of meningiomas. J Pathol Trans Med. (2020) 54:45-63. doi: 10.4132/jptm.2019.11.05

9. Perry A, Scheithauer BW, Stafford SL, Lohse CM, Wollan PC. "Malignancy" in meningiomas: a clinicopathologic study of 116 patients, with grading 
implications. Cancer. (1999) 85:2046-56. doi: 10.1002/(SICI)10970142(19990501)85:9\%3C2046::AID-CNCR23\%3E3.0.CO;2-M

10. Peæina-Šlaus N, Kafka A, Lechpammer M. Molecular genetics of intracranial meningiomas with emphasis on canonical wnt signalling. Cancers. (2016) 8:67. doi: 10.3390/cancers8070067

11. Leone PE, Bello MJ, de Campos JM, Vaquero J, Sarasa JL, Pestaña A, et al. NF2 gene mutations and allelic status of $1 \mathrm{p}, 14 \mathrm{q}$ and $22 \mathrm{q}$ in sporadic meningiomas. Oncogene. (1999) 18:2231-9. doi: 10.1038/sj.onc.1202531

12. Yao L, Alahmari M, Temel Y, Hovinga K. Therapy of sporadic and NF2-related vestibular schwannoma. Cancers. (2020) 12:835. doi: 10.3390/ cancers 12040835

13. Lee $\mathrm{CH}$, Chung $\mathrm{CK}$, Ohn JH, Kim CH. The similarities and differences between intracranial and spinal ependymomas : a review from a genetic research perspective. J Korean Neurosurg Soc. (2016) 59:83-90. doi: 10.3340/ jkns.2016.59.2.83

14. Quetel L, Meiller C, Assié JB, Blum Y, Imbeaud S, Montagne F, et al. Genetic alterations of malignant pleural mesothelioma: association with tumor heterogeneity and overall survival. Mol Oncol. (2020) 14:1207-23. doi: $10.1002 / 1878-0261.12651$

15. McClatchey AI, Saotome I, Mercer K, Crowley D, Gusella JF, Bronson RT, et al. Mice heterozygous for a mutation at the Nf2 tumor suppressor locus develop a range of highly metastatic tumors. Genes Dev. (1998) 12:1121-33. doi: $10.1101 /$ gad.12.8.1121

16. McClatchey AI, Fehon RG. Merlin and the ERM proteins-regulators of receptor distribution and signaling at the cell cortex. Trends Cell Biol. (2009) 19:198-206. doi: 10.1016/j.tcb.2009.02.006

17. Riemenschneider MJ, Perry A, Reifenberger G. Histological classification and molecular genetics of meningiomas. Lancet Neurol. (2006) 5:1045-54. doi: 10.1016/S1474-4422(06)70625-1

18. Lamszus K. Meningioma pathology, genetics, and biology. J Neuropathol Exp Neurol. (2004) 63:275-86. doi: 10.1093/jnen/63.4.275

19. Domingues PH, Sousa P, Otero Á, Gonçalves JM, Ruiz L, de Oliveira C, et al. Proposal for a new risk stratification classification for meningioma based on patient age, WHO tumor grade, size, localization, and karyotype. Neuro Oncol. (2014) 16:735-47. doi: 10.1093/neuonc/not325

20. Ve Clark EZ, Erson-Omay AS, Yin J, Cotney J, Ozduman K, Avşar T, et al. Genomic analysis of non-NF2 meningiomas reveals mutations in TRAF7, KLF4, AKT1, and SMO. Science (New York N Y). (2013) 339:1077-80. doi: $10.1126 /$ science. 1233009

21. Abedalthagafi M, Bi WL, Aizer AA, Merrill PH, Brewster R, Agarwalla PK, et al. Oncogenic PI3K mutations are as common as AKT1 and SMO mutations in meningioma. Neuro Oncol. (2016) 18:649-55. doi: 10.1093/ neuonc/nov316

22. Spiegl-Kreinecker S, Lötsch D, Neumayer K, Kastler L, Gojo J, Pirker C, et al. TERT promoter mutations are associated with poor prognosis and cell immortalization in meningioma. Neuro Oncol. (2018) 20:1584-93. doi: 10.1093/neuonc/noy104

23. Sahm F, Schrimpf D, Olar A, Koelsche C, Reuss D, Bissel J, et al. TERT promoter mutations and risk of recurrence in meningioma. J Natl Cancer Institute. (2016) 16:108. doi: 10.1093/jnci/djv377

24. Ta Juratli D, McCabe NN, Williams EA, Silverman IM, Tummala SS, Fink AL, et al. DMD genomic deletions characterize a subset of progressive/highergrade meningiomas with poor outcome. Acta Neuropathol. (2018) 136:77992.

25. Gm Shankar M, Abedalthagafi RAV, Merrill PH, Nayyar N, Gill CM, Brewster $\mathrm{R}$, et al. Germline and somatic BAP1 mutations in high-grade rhabdoid meningiomas. Neuro Oncol. (2017) 19:535-45. doi: 10.1093/neuonc/now235

26. Boström J, Meyer-Puttlitz B, Wolter M, Blaschke B, Weber RG, Lichter P, et al. Alterations of the tumor suppressor genes CDKN2A (p16(INK4a)), p14(ARF), CDKN2B (p15(INK4b)), and CDKN2C (p18(INK4c)) in atypical and anaplastic meningiomas. Am J Pathol. (2001) 159:661-9. doi: 10.1016/ S0002-9440(10)61737-3

27. Cheng G, Zhang L, Lv W, Dong C, Wang Y, Zhang J. Overexpression of cyclin D1 in meningioma is associated with malignancy grade and causes abnormalities in apoptosis, invasion and cell cycle progression. Med Oncol (Northwood Lond Engl). (2015) 32:439. doi: 10.1007/s12032-0140439-0
28. Guyot A, Duchesne M, Robert S, Lia AS, Derouault P, Scaon E, et al. Analysis of CDKN2A gene alterations in recurrent and non-recurrent meningioma. $J$ Neuro Oncol. (2019) 145:449-59. doi: 10.1007/s11060-019-03333-6

29. Perry A, Banerjee R, Lohse CM, Kleinschmidt-DeMasters BK, Scheithauer BW. A role for chromosome 9p21 deletions in the malignant progression of meningiomas and the prognosis of anaplastic meningiomas. Brain Pathol (Zurich Switzerland). (2002) 12:183-90. doi: 10.1111/j.1750-3639.2002. tb00433.x

30. Qie S, Diehl JA. Cyclin D1, cancer progression, and opportunities in cancer treatment. J Mol Med (Berlin Germany). (2016) 94:1313-26. doi: 10.1007/ s00109-016-1475-3

31. Alvarez-Fernández M, Medema RH. Novel functions of FoxM1: from molecular mechanisms to cancer therapy. Front Oncol. (2013) 3:30. doi: 10.3389/fonc. 2013.00030

32. Liang C, Zhang X, Yang M, Dong X. Recent progress in ferroptosis inducers for cancer therapy. Adv Mater. (2019) 31:e1904197. doi: 10.1002/adma. 201904197

33. Vasudevan HN, Braunstein SE, Phillips JJ, Pekmezci M, Tomlin BA, Wu $\mathrm{A}$, et al. Comprehensive molecular profiling identifies FOXM1 as a key transcription factor for meningioma proliferation. Cell Rep. (2018) 22:367283. doi: $10.1016 /$ j.celrep.2018.03.013

34. Ohta S, Taniguchi T, Sato N, Hamada M, Taniguchi H, Rappsilber J. Quantitative proteomics of the mitotic chromosome scaffold reveals the association of BAZ1B with chromosomal axes. Mol Cell Proteom MCP. (2019) 18:169-81. doi: 10.1074/mcp.RA118.000923

35. Winther TL, Torp SH. DNA topoisomerase II $\alpha$ and mitosin expression predict meningioma recurrence better than histopathological grade and MIB-1 after initial surgery. PLoS One. (2019) 12:e0172316. doi: 10.1371/ journal.pone. 0172316

36. Pachow D, Wick W, Gutmann DH, Mawrin C. The mTOR signaling pathway as a treatment target for intracranial neoplasms. Neuro Oncol. (2015) 17:18999. doi: 10.1093/neuonc/nou164

37. Mei Y, Du Z, Hu C, Greenwald NF, Abedalthagafi M, Agar NYR, et al. Osteoglycin promotes meningioma development through downregulation of NF2 and activation of mTOR signaling. Cell Commun Signal CCS. (2017) 15:34. doi: 10.1186/s12964-017-0189-7

38. Yesilöz Ü, Kirches E, Hartmann C, Scholz J, Kropf S, Sahm F, et al. Frequent AKT1E17K mutations in skull base meningiomas are associated with mTOR and ERK1/2 activation and reduced time to tumor recurrence. Neuro Oncol. (2017) 19:1088-96. doi: 10.1093/neuonc/nox018

39. Barresi V, Lionti S, La Rocca L, Caliri S, Caffo M. High p-mTOR expression is associated with recurrence and shorter disease-free survival in atypical meningiomas. Neuropathology. (2019) 39:22-9. doi: 10.1111/neup.12524

40. Zhou K, Wang G, Wang Y, Jin H, Yang S, Liu C. The potential involvement of E-cadherin and beta-catenins in meningioma. PLoS One. (2010) 5:e11231. doi: 10.1371/journal.pone.0011231

41. Arikkath J, Reichardt LF. Cadherins and catenins at synapses: roles in synaptogenesis and synaptic plasticity. Trends Neurosci. (2008) 31:487-94. doi: 10.1016/j.tins.2008.07.001

42. Zidar N, Gale N, Kojc N, Volavsek M, Cardesa A, Alos L, et al. Cadherincatenin complex and transcription factor Snail-1 in spindle cell carcinoma of the head and neck. Virchows Archiv. (2008) 453:267-74. doi: 10.1007/s00428008-0649-y

43. Pećina-Slaus N, Nikuseva Martić T, Deak AJ, Zeljko M, Hrasćan R, Tomas D, et al. Genetic and protein changes of E-cadherin in meningiomas. J Cancer Res Clin Oncol. (2010) 136:695-702. doi: 10.1007/s00432-009-0708-z

44. Foda AAM, Alam MS, Ikram N, Rafi S, Elnaghi K. Spinal versus intracranial meningioma: expression of E-cadherin and Fascin with relation to clinicopathological features. Cancer Biomarkers Sect A Dis Markers. (2019) 25:333-9. doi: 10.3233/CBM-190164

45. Wallesch M, Pachow D, Blücher C, Firsching R, Warnke JP, Braunsdorf WEK, et al. Altered expression of E-Cadherin-related transcription factors indicates partial epithelial-mesenchymal transition in aggressive meningiomas. $J$ Neurol Sci. (2017) 380:112-21. doi: 10.1016/j.jns.2017.07.009

46. Huang H. , Matrix metalloproteinase-9 (MMP-9) as a cancer biomarker and MMP-9 biosensors: recent advances. Sensors (Basel Switzerland). (2018) 18:3249. doi: 10.3390/s18103249 
47. Tian Y, Guo Y, Zhu P, Zhang D, Liu S, Tang M, et al. TRIM59 loss in M2 macrophages promotes melanoma migration and invasion by upregulating MMP-9 and Madcam1. Aging. (2019) 11:8623-41. doi: 10.18632/aging. 102351

48. Chen YT, Yang CC, Shao PL, Huang CR, Yip HK. Melatonin-mediated downregulation of ZNF746 suppresses bladder tumorigenesis mainly through inhibiting the AKT-MMP-9 signaling pathway. J Pineal Res. (2019) 66:e12536. doi: 10.1111/jpi.12536

49. Tzeng HE, Tang CH, Wu SH, Chen HT, Fong YC, Lu YC, et al. CCN6-mediated MMP-9 activation enhances metastatic potential of human chondrosarcoma. Cell Death Dis. (2018) 9:955. doi: 10.1038/s41419-0181008-9

50. Lee S, Lee E, Ko E, Ham M, Lee HM, Kim ES, et al. Tumor-associated macrophages secrete CCL2 and induce the invasive phenotype of human breast epithelial cells through upregulation of ERO1- $\alpha$ and MMP-9. Cancer Lett. (2018) 437:25-34. doi: 10.1016/j.canlet.2018.08.025

51. Xing H, Wang S, Li Q, Ma Y, Sun P. Long noncoding RNA LINC00460 targets miR-539/MMP-9 to promote meningioma progression and metastasis. Biomed Pharmacother Biomed Pharmacother. (2018) 105:677-82. doi: 10. 1016/j.biopha.2018.06.005

52. Reszec J, Hermanowicz A, Rutkowski R, Turek G, Mariak Z, Chyczewski L. Expression of MMP-9 and VEGF in meningiomas and their correlation with peritumoral brain edema. BioMed Res Int. (2015) 2015:646853. doi: $10.1155 / 2015 / 646853$

53. Gogineni VR, Kargiotis O, Klopfenstein JD, Gujrati M, Dinh DH, Rao JS. RNAi-mediated downregulation of radiation-induced MMP-9 leads to apoptosis via activation of ERK and Akt in IOMM-Lee cells. Int J Oncol. (2009) 34:209-18.

54. Petermann A, Haase D, Wetzel A, Balavenkatraman KK, Tenev T, Gührs $\mathrm{KH}$, et al. Loss of the protein-tyrosine phosphatase DEP-1/PTPRJ drives meningioma cell motility. Brain Pathol (Zurich Switzerland). (2011) 21:40518. doi: 10.1111/j.1750-3639.2010.00464.x

55. Petermann A, Stampnik Y, Cui Y, Morrison H, Pachow D, Kliese N, et al. Deficiency of the protein-tyrosine phosphatase DEP-1/PTPRJ promotes matrix metalloproteinase-9 expression in meningioma cells. J Neuro Oncol. (2015) 122:451-9. doi: 10.1007/s11060-015-1740-2

56. Waldt N, Scharnetzki D, Kesseler C, Kirches E, Stroscher N, Böhmer FD, et al. Loss of PTPRJ/DEP-1 enhances NF2/Merlin-dependent meningioma development. J Neurol Sci. (2020) 408:116553. doi: 10.1016/j.jns.2019.116553

57. Huang Q, Zhao SL, Tian XY, Li B, Li Z. Increased co-expression of macrophage migration inhibitory factor and matrix metalloproteinase 9 is associated with tumor recurrence of meningioma. Int J Med Sci. (2013) 10:276-85. doi: 10.7150/ijms.5185

58. Benz PM, Ding Y, Stingl H, Loot AE, Zink J, Wittig I, et al. AKAP12 deficiency impairs VEGF-induced endothelial cell migration and sprouting. Acta Physiol (Oxford England). (2020) 228:e13325. doi: 10.1111/apha. 13325

59. Finger EC, Castellini L, Rankin EB, Vilalta M, Krieg AJ, Jiang D, et al. Hypoxic induction of AKAP12 variant 2 shifts PKA-mediated protein phosphorylation to enhance migration and metastasis of melanoma cells. Proc Natl Acad Sci USA. (2015) 112:4441-6. doi: 10.1073/pnas.1418164112

60. Han S, Wang L, Sun L, Wang Y, Yao B, Chen T, et al. MicroRNA-1251$5 \mathrm{p}$ promotes tumor growth and metastasis of hepatocellular carcinoma by targeting AKAP12. Biomed Pharmacother Biomed Pharmacother. (2020) 122:109754. doi: 10.1016/j.biopha.2019.109754

61. Zhang J, Piao HY, Guo S, Wang Y, Zhang T, Zheng ZC, et al. LINC00163 inhibits the invasion and metastasis of gastric cancer cells as a ceRNA by sponging miR-183 to regulate the expression of AKAP12. Int J Clin Oncol. (2020) 25:570-83. doi: 10.1007/s10147-019-01604-w

62. Soh RYZ, Lim JP, Samy RP, Chua PJ, Bay BH. A-kinase anchor protein 12 (AKAP12) inhibits cell migration in breast cancer. Exp Mol Pathol. (2018) 105:364-70. doi: 10.1016/j.yexmp.2018.10.010

63. Parada CA, Osbun J, Kaur S, Yakkioui Y, Shi M, Pan C, et al. Kinome and phosphoproteome of high-grade meningiomas reveal AKAP12 as a central regulator of aggressiveness and its possible role in progression. Sci Rep. (2018) 8:2098. doi: 10.1038/s41598-018-19308-y

64. Pistolesi S, Boldrini L, Gisfredi S, De Ieso K, Camacci T, Caniglia M, et al. Angiogenesis in intracranial meningiomas: immunohistochemical and molecular study. Neuropathol Appl Neurobiol. (2004) 30:118-25. doi: 10. 1046/j.0305-1846.2003.00516.x

65. Bergers G, Benjamin LE. Tumorigenesis and the angiogenic switch. Nature reviews. Cancer. (2003) 3:401-10. doi: 10.1038/nrc1093

66. Preusser M, Hassler M, Birner P, Rudas M, Acker T, Plate KH, et al. Microvascularization and expression of VEGF and its receptors in recurring meningiomas: pathobiological data in favor of anti-angiogenic therapy approaches. Clin Neuropathol. (2012) 31:352-60. doi: 10.5414/NP300488

67. Ye J, Li Y, Hamasaki T, Nakamichi N, Komatsu T, Kashiwagi T, et al. Inhibitory effect of electrolyzed reduced water on tumor angiogenesis. Biol Pharm Bull. (2008) 31:19-26. doi: 10.1248/bpb.31.19

68. Semenza GL. Defining the role of hypoxia-inducible factor 1 in cancer biology and therapeutics. Oncogene. (2010) 29:625-34. doi: 10.1038/onc. 2009.441

69. Karar J, Maity A. PI3K/AKT/mTOR pathway in angiogenesis. Front Mol Neurosci. (2011) 4:51. doi: 10.3389/fnmol.2011.00051

70. Carmeliet P, Jain RK. Molecular mechanisms and clinical applications of angiogenesis. Nature. (2011) 473:298-307. doi: 10.1038/nature10144

71. Ando H, Natsume A, Iwami K, Ohka F, Kuchimaru T, Kizaka-Kondoh S, et al. A hypoxia-inducible factor (HIF)- $3 \alpha$ splicing variant, HIF-3 $\alpha 4$ impairs angiogenesis in hypervascular malignant meningiomas with epigenetically silenced HIF-3a4. Biochem Biophys Res Commun. (2013) 433:139-44. doi: 10.1016/j.bbrc.2013.02.044

72. Aggarwal BB, Sethi G, Ahn KS, Sandur SK, Pandey MK, Kunnumakkara $A B$, et al. Targeting signal-transducer-and-activator-of-transcription-3 for prevention and therapy of cancer: modern target but ancient solution. Ann N Y Acad Sci. (2006) 1091:151-69. doi: 10.1196/annals.1378.063

73. Kwon MJ, Sung CO, Kang SY, Do IG, Suh YL. Differential expression of extracellular matrix-related genes in rare variants of meningioma. Hum Pathol. (2013) 44:260-8. doi: 10.1016/j.humpath.2012.05.019

74. Tummalapalli P, Gondi CS, Dinh DH, Gujrati M, Rao JS. RNA interferencemediated targeting of urokinase plasminogen activator receptor and matrix metalloproteinase-9 gene expression in the IOMM-lee malignant meningioma cell line inhibits tumor growth, tumor cell invasion and angiogenesis. Int J Oncol. (2007) 31:5-17. doi: 10.3892/ijo.31.1.5

75. Maniotis AJ, Folberg R, Hess A, Seftor EA, Gardner LM, Pe'er J, et al. Vascular channel formation by human melanoma cells in vivo and in vitro: vasculogenic mimicry. Am J Pathol. (1999) 155:739-52. doi: 10.1016/S00029440(10)65173-5

76. Saydam O, Shen Y, Würdinger T, Senol O, Boke E, James MF, et al. Downregulated microRNA-200a in meningiomas promotes tumor growth by reducing E-cadherin and activating the Wnt/beta-catenin signaling pathway. Mol Cell Biol. (2009) 29:5923-40. doi: 10.1128/MCB.00332-09

77. Zhang Y, Yu R, Li Q, Li Y, Xuan T, Cao S, et al. SNHG1/miR-556-5p/TCF12 feedback loop enhances the tumorigenesis of meningioma through Wnt signaling pathway. J Cell Biochem. (2020) 121:1880-9. doi: 10.1002/jcb.29423

78. Shi ZZ, Fan ZW, Chen YX, Xie XF, Jiang W, Wang WJ, et al. Ferroptosis in carcinoma: regulatory mechanisms and new method for cancer therapy. Onco Targets Ther. (2019) 12:11291-304. doi: 10.2147/OTT.S232852

79. Sharma S, Ray S, Mukherjee S, Moiyadi A, Sridhar E, Srivastava S. Multipronged quantitative proteomic analyses indicate modulation of various signal transduction pathways in human meningiomas. Proteomics. (2015) 15:394-407. doi: 10.1002/pmic.201400328

80. Lien WH, Fuchs E. Wnt some lose some: transcriptional governance of stem cells by Wnt/ $\beta$-catenin signaling. Genes Dev. (2014) 28:1517-32. doi: 10.1101/gad.244772.114

81. Mavila N, Thundimadathil J. The emerging roles of cancer stem cells and wnt/beta-catenin signaling in hepatoblastoma. Cancers. (2019) 11:1406. doi: $10.3390 /$ cancers 11101406

82. Fagotto F. Looking beyond the Wnt pathway for the deep nature of $\beta$-catenin. EMBO Rep. (2013) 14:422-33. doi: 10.1038/embor.2013.45

83. Mazieres J, He B, You L, Xu Z, Jablons DM. Wnt signaling in lung cancer. Cancer Lett. (2005) 222:1-10. doi: 10.1016/j.canlet.2004.08.040

84. Luu HH, Zhang R, Haydon RC, Rayburn E, Kang Q, Si W, et al. Wnt/betacatenin signaling pathway as a novel cancer drug target. Curr Cancer Drug Targets. (2004) 4:653-71. doi: 10.2174/1568009043332709

85. Li Q, Shen K, Zhao Y, Ma C, Liu J, Ma J. MiR-92b inhibitor promoted glioma cell apoptosis via targeting DKK3 and blocking the Wnt/beta-catenin 
signaling pathway. J Trans Med. (2013) 11:302. doi: 10.1186/1479-5876-11302

86. Li C, Jiao G, Wu W, Wang H, Ren S, Zhang L, et al. Exosomes from bone marrow mesenchymal stem cells inhibit neuronal apoptosis and promote motor function recovery via the $\mathrm{Wnt} / \beta$-catenin signaling pathway. Cell Trans. (2019) 28:1373-83. doi: 10.1177/09636897198 70999

87. Che QQ, Huang T, Zhang YD, Qian XJ. Effect of miR-124 on neuronal apoptosis in rats with cerebral infarction through Wnt/B-catenin signaling pathway. Eur Rev Med Pharmacol Sci. (2019) 23:6657-64.

88. Yao Y, Gao Z, Liang W, Kong L, Jiao Y, Li S, et al. Osthole promotes neuronal differentiation and inhibits apoptosis via $\mathrm{Wnt} / \beta$-catenin signaling in an Alzheimer's disease model. Toxicol Appl Pharmacol. (2015) 289:474-81. doi: 10.1016/j.taap.2015.10.013

89. Gao K, Shen Z, Yuan Y, Han D, Song C, Guo Y, et al. Simvastatin inhibits neural cell apoptosis and promotes locomotor recovery via activation of Wnt/B-catenin signaling pathway after spinal cord injury. $J$ Neurochem. (2016) 138:139-49. doi: 10.1111/jnc.13382

90. Tian XH, Hou WJ, Fang Y, Fan J, Tong H, Bai SL, et al. XAV939, a tankyrase 1 inhibitior, promotes cell apoptosis in neuroblastoma cell lines by inhibiting Wnt/ $\beta$-catenin signaling pathway. J Exp Clin Cancer Res CR. (2013) 32:100. doi: 10.1186/1756-9966-32-100

91. Ruan W, Hu J, Zhou H, Li Y, Xu C, Luo Y, et al. Intranasal wnt-3a alleviates neuronal apoptosis in early brain injury post subarachnoid hemorrhage via the regulation of wnt target PPAN mediated by the moonlighting role of aldolase C. Neurochem Int. (2020) 134:104656. doi: 10.1016/j.neuint.2019. 104656

92. Kanno H, Nishihara H, Wang L, Yuzawa S, Kobayashi H, Tsuda M, et al. Expression of CD163 prevents apoptosis through the production of granulocyte colony-stimulating factor in meningioma. Neuro Oncol. (2013) 15:853-64. doi: 10.1093/neuonc/not028

93. Jiang C, Song T, Li J, Ao F, Gong X, Lu Y, et al. RAS promotes proliferation and resistances to apoptosis in meningioma. Mol Neurobiol. (2017) 54:779-87. doi: $10.1007 / \mathrm{s} 12035-016-9763-\mathrm{z}$

94. Li H, Zhao J. let-7d suppresses proliferation and invasion and promotes apoptosis of meningioma by targeting AEG-1. OncoTargets Therapy. (2017) 10:4895-904. doi: 10.2147/OTT.S141008

95. Kotipatruni RP, Ren X, Thotala D, Jaboin JJ. NDRG4 is a novel oncogenic protein and p53 associated regulator of apoptosis in malignant meningioma cells. Oncotarget. (2015) 6:17594-604. doi: 10.18632/oncotarget.4009

96. Yan L, Li-Hong Z, Qi L. Research hotspot and frontier progress of cancer under the background of precision medicine. 1. Tradit Med Res. (2020) 5:22-33.

97. Pachow D, Andrae N, Kliese N, Angenstein F, Stork O, Wilisch-Neumann A, et al. mTORC1 inhibitors suppress meningioma growth in mouse models. Clin Cancer Res. (2013) 19:1180-9. doi: 10.1158/1078-0432.CCR-121904

98. Graillon T, Sanson M, Campello C, Idbaih A, Peyre M, Peyrière H, et al. Everolimus and octreotide for patients with recurrent meningioma: results from the phase II CEVOREM trial. Clin Cancer Res. (2020) 26:552-7. doi: 10.1158/1078-0432.CCR-19-2109

99. Graillon T, Romano D, Defilles C, Saveanu A, Mohamed A, FigarellaBranger D, et al. Octreotide therapy in meningiomas: in vitro study, clinical correlation, and literature review. J Neurosurg. (2017) 127:660-9. doi: 10. 3171/2016.8.JNS16995

100. Graillon T, Defilles C, Mohamed A, Lisbonis C, Germanetti AL, Chinot $\mathrm{O}$, et al. Combined treatment by octreotide and everolimus: Octreotide enhances inhibitory effect of everolimus in aggressive meningiomas. J Neuro Oncol. (2015) 124:33-43. doi: 10.1007/s11060-015-1812-3

101. Lamszus K, Lengler U, Schmidt NO, Stavrou D, Ergün S, Westphal M. Vascular endothelial growth factor, hepatocyte growth factor/scatter factor, basic fibroblast growth factor, and placenta growth factor in human meningiomas and their relation to angiogenesis and malignancy. Neurosurgery. (2000) 46:938-47; discussion 947-8. doi: 10.1227/00006123200004000-00033
102. Nayak L, Iwamoto FM, Rudnick JD, Norden AD, Lee EQ, Drappatz J, et al. Atypical and anaplastic meningiomas treated with bevacizumab. J Neuro Oncol. (2012) 109:187-93. doi: 10.1007/s11060-012-0886-4

103. Lou E, Sumrall AL, Turner S, Peters KB, Desjardins A, Vredenburgh JJ, et al. Bevacizumab therapy for adults with recurrent/progressive meningioma: a retrospective series. J Neuro Oncol. (2012) 109:63-70. doi: 10.1007/s11060012-0861-0

104. Shih KC, Chowdhary S, Rosenblatt P, Weir AB, Shepard GC, Williams JT, et al. A phase II trial of bevacizumab and everolimus as treatment for patients with refractory, progressive intracranial meningioma. J Neuro Oncol. (2016) 129:281-8. doi: 10.1007/s11060-016-2172-3

105. Kaley TJ, Wen P, Schiff D, Ligon K, Haidar S, Karimi S, et al. trial of sunitinib for recurrent and progressive atypical and anaplastic meningioma. Neuro Oncol. (2015) 17:116-21. doi: 10.1093/neuonc/nou148

106. Nigim F, Wakimoto H, Kasper EM, Ackermans L, Temel Y. Emerging medical treatments for meningioma in the molecular Era. Biomedicines. (2018) 6:36. doi: 10.3390/biomedicines6030086

107. Chamberlain MC, Tsao-Wei DD, Groshen S. Temozolomide for treatmentresistant recurrent meningioma. Neurology. (2004) 62:1210-2. doi: 10.1212/ 01.WNL.0000118300.82017.F4

108. Chamberlain MC, Tsao-Wei DD, Groshen S. Salvage chemotherapy with CPT-11 for recurrent meningioma. J Neuro Oncol. (2006) 78:271-6. doi: 10.1007/s11060-005-9093-x

109. Mason WP, Gentili F, Macdonald DR, Hariharan S, Cruz CR, Abrey LE. Stabilization of disease progression by hydroxyurea in patients with recurrent or unresectable meningioma. J Neurosurgery. (2002) 97:341-6. doi: 10.3171/ jns.2002.97.2.0341

110. Koper JW, Zwarthoff EC, Hagemeijer A, Braakman R, Avezaat CJ, Bergström $\mathrm{M}$, et al. Inhibition of the growth of cultured human meningioma cells by recombinant interferon-alpha. Eur J Cancer (Oxford Engl 1990). (1991) 27:416-9. doi: 10.1016/0277-5379(91)90375-N

111. Chamberlain MC, Glantz MJ. Interferon-alpha for recurrent World Health Organization grade 1 intracranial meningiomas. Cancer. (2008) 113:2146-51. doi: $10.1002 /$ cncr. 23803

112. Du Z, Abedalthagafi M, Aizer AA, McHenry AR, Sun HH, Bray MA, et al. Increased expression of the immune modulatory molecule PD-L1 (CD274) in anaplastic meningioma. Oncotarget. (2015) 6:4704-16. doi: 10.18632/ oncotarget. 3082

113. Hsu DW, Efird JT, Hedley-Whyte ET. Progesterone and estrogen receptors in meningiomas: prognostic considerations. J Neurosurgery. (1997) 86:113-20. doi: 10.3171 /jns.1997.86.1.0113

114. Touat M, Lombardi G, Farina P, Kalamarides M, Sanson M. Successful treatment of multiple intracranial meningiomas with the antiprogesterone receptor agent mifepristone (RU486). Acta Neurochirur. (2014) 156:1831-5. doi: 10.1007/s00701-014-2188-4

115. Grunberg SM, Weiss MH, Russell CA, Spitz IM, Ahmadi J, Sadun A, et al. Long-term administration of mifepristone (RU486): clinical tolerance during extended treatment of meningioma. Cancer Investigation. (2006) 24:727-33. doi: 10.1080/07357900601062339

116. Ji Y, Rankin C, Grunberg S, Sherrod AE, Ahmadi J, Townsend JJ, et al. Randomized trial of the antiprogestin agent mifepristone in the treatment of unresectable meningioma: SWOG S9005. J Clin Oncol. (2015) 33:4093-8. doi: 10.1200/JCO.2015.61.6490

Conflict of Interest: The authors declare that the research was conducted in the absence of any commercial or financial relationships that could be construed as a potential conflict of interest.

Copyright (c) 2020 Shao, Liu, Zheng, Tu, Pan, Yan, Wei, Shao and Zhang. This is an open-access article distributed under the terms of the Creative Commons Attribution License (CC BY). The use, distribution or reproduction in other forums is permitted, provided the original author(s) and the copyright owner(s) are credited and that the original publication in this journal is cited, in accordance with accepted academic practice. No use, distribution or reproduction is permitted which does not comply with these terms. 